\title{
AUGE Y CAÍDA DE NUEVAS NATURALEZAS URBANAS: PLANTAS ORNAMENTALES Y EXPANSIÓN TURÍSTICO-RESIDENCIAL EN ALICANTE ${ }^{1}$
}

\author{
María Hernández Hernández \\ Instituto Interuniversitario de Geografía. Universidad de Alicante \\ maria.hernandez@ua.es \\ David Sauri Puyol \\ Departamento de Geografía. Universidad Autónoma de Barcelona \\ david.sauri@uab.cat \\ Alfredo Morales Gil \\ Instituto Interuniversitario de Geografía. Universidad de Alicante \\ alfredo.morales@ua.es
}

\section{RESUMEN}

La expansión residencial acaecida en el litoral español desde 1998 ha generado notables repercusiones territoriales. En este artículo, se analizan las relaciones que se establecen entre la expansión residencial y los cambios en el modelo urbano-residencial. La difusión de áreas ajardinas ha supuesto también cambios en el sistema productivo local. Se han consolidado, por un lado, empresas productoras de flores y planta ornamental y, por otro, centros que ofertan servicios y plantas. El análisis de variables como localización, tamaño o servicios prestados refleja la existencia de diferencias en el modelo residencial en este sector litoral, pero también en su intensidad y grado de implantación.

Palabras clave: expansión residencial, jardines, consumos hídricos, zonas semiáridas, España, garden center, explotación agrícola, planta ornamental.

Fecha de recepción: marzo 2013.

Fecha de aceptación: enero 2014.

1 Este artículo se inserta en los proyectos de investigación «Modelos de desarrollo territorial y tipologías de consumo de agua potable en espacios turístico residenciales del litoral alicantino» (CSO2009-12772-C03-03), «Procesos de urbanización reciente y gestión sostenible del agua: una exploración de relaciones para el litoral mediterráneo de la península Ibérica» (CSO2009-12772-03-01), «Urbanización y metabolismo hídrico en el litoral de Alicante: análisis de tendencias para el periodo 2000-2010»(CSO2012-36997-C02-02) y «Análisis de los cambios recientes en el consumo de agua en entornos de urbanización acelerada: propuesta metodológica y estudio de caso para el litoral Mediterráneo español» (CSO2012-36997-C02-01) financiados por el Ministerio de Ciencia y Tecnología y por el Ministerio de Economía y Competitividad. 


\section{ABSTRACT}

Urban sprawl occurred in the Spanish coast since 1990`s has generated a notable territorial impact. In this article, it is analyzed the relationships established between urban sprawl and changes on urban model. The spread of garden areas has also meant changes in the local productive system. It has been consolidated, on the one hand, flowers and ornamental plants producers and, by another one, garden centers that offer services and plants. The analysis of items such as location, size, provided services provided, etc. reflects the existence of differences in the urban model in this coastal area, but also in its intensity and development degree.

Keywords: urban sprawl, garden, water consumption, semi-arid regions, Spain, garden center, farm, an ornamental plant.

\section{INTRODUCCIÓN: EXPANSIÓN RESIDENCIAL Y CAMBIOS EN LAS TIPOLOGÍAS URBANAS}

El informe sobre el Estado del Medio Ambiente elaborado por la Agencia Europea de Medio Ambiente en 2002 (EEA, 2002) ponía de manifiesto que en los últimos veinte años la superficie edificada de Europa había crecido un $20 \%$. Alertando acerca de las repercusiones que esta dinámica podría tener sobre recursos como el agua o el suelo, las demandas energéticas o la generación de residuos. En un informe posterior, Urban sprawl (EEA, 2006), se insistía en la denominada expansión urbana; entendiendo por ello cuando la tasa de cambio del uso del suelo de rústico a urbano es superior a la de crecimiento demográfico de una determinada zona durante un período establecido. Este proceso ha sido muy evidente en algunos ejes de crecimiento económico europeo como es el mediterráneo. Tan sólo en el sector español del Arco Mediterráneo (el llamado Sunbelt europeo), en el período 1992-2000, se construyeron más de un millón doscientas mil nuevas viviendas, con lo que ello supone de incremento del consumo de agua potable y de energía, de demanda de servicios educativos, sanitarios y culturales y de generación de residuos orgánicos e inorgánicos y de aguas residuales, que deben ser tratados, lo que requiere, a su vez, la ampliación de esas instalaciones o la construcción de nuevas.

La expansión residencial acaecida en el litoral mediterráneo español desde finales de los años noventa del siglo XX hasta 2008 ha generado notables repercusiones territoriales, fácilmente identificables en el cambio en el uso del suelo y en las transformaciones paisajísticas. El número total de viviendas en España se incrementó en casi cinco millones entre el año 2001 y el 2011 (Ministerio de Fomento, 2012a), aproximadamente un 25\%, al pasar el parque de viviendas de 21,03 a 26,01 millones, respectivamente. Porcentaje que se concentra mayoritariamente entre 2001 y 2008, coincidiendo con el denominado boom de la construcción. Tendencia que se ralentiza a partir de 2007, cuando se inicia la actual crisis inmobiliaria. Este espectacular ritmo de crecimiento se inicia en la década de los noventa, cuando el parque de viviendas se elevaba a 17,2 millones de unidades residenciales (Taltavull, 2001). Esta progresión se confirma, asimismo, al consultar el número de viviendas visadas, es decir, aquellas que están en condiciones de ser habitadas y de contar con el oportuno servicio de suministro de agua potable y de saneamiento. Según los datos proporcionados por el Minis- 
terio de Fomento, en el período 2001-2011, el número de viviendas visadas se elevaba a 5,6 millones. Datos que nos situarían ante porcentajes superiores a los registrados en la década de los años sesenta, coincidiendo con la denominada etapa del desarrollismo español. Esa dinámica ha significado un incremento de la superficie urbanizada con finalidad residencial de unos 932 millones de $\mathrm{m}^{2}$ entre el año 2000 y 2011 (Ministerio de Fomento, 2012c). Cifra que contrasta con los 450 del decenio anterior (1990-1999).

Este intenso desarrollo urbano presenta una marcada concentración territorial. Por regiones, Andalucía (1.115.659 viviendas), Cataluña (769.786), Comunidad Valenciana (791.882), Murcia (292.708) y Baleares (118.069) acumulan más de 3 millones de certificaciones de fin de obra, lo que supone aproximadamente el 55\% del total nacional. La Valenciana, por ejemplo, entre 1997 y 2008, fue la tercera comunidad autónoma en número de viviendas iniciadas en esa década. En este periodo, se construyeron unas 790.000 unidades residenciales, lo que supuso un incremento del 36\% con respecto a las existentes en 1996 (Burriel, 2009a). Esta concentración regional se acentúa todavía más a escala provincial. Las 11 provincias ribereñas del mediterráneo (figura 1) suman 2.487.262 nuevas viviendas visadas para el periodo 2000-2011, lo que supone el 43,88\% del total estatal (tabla 1). Sorprendente resulta esta actividad en la provincia de Alicante que la situó en el tercer puesto del ranking nacional (345.410) tras Madrid y Barcelona, y por encima de provincias de mayor entidad poblacional (población de derecho) como Valencia o Málaga, en la propia fachada mediterránea española, o de Sevilla.

EVOLUCIÓN DE LA CONSTRUCCIÓN DE VIVIENDAS (Nº) EN LA FACHADA MEDITERRÁNEA ESPAÑOLA

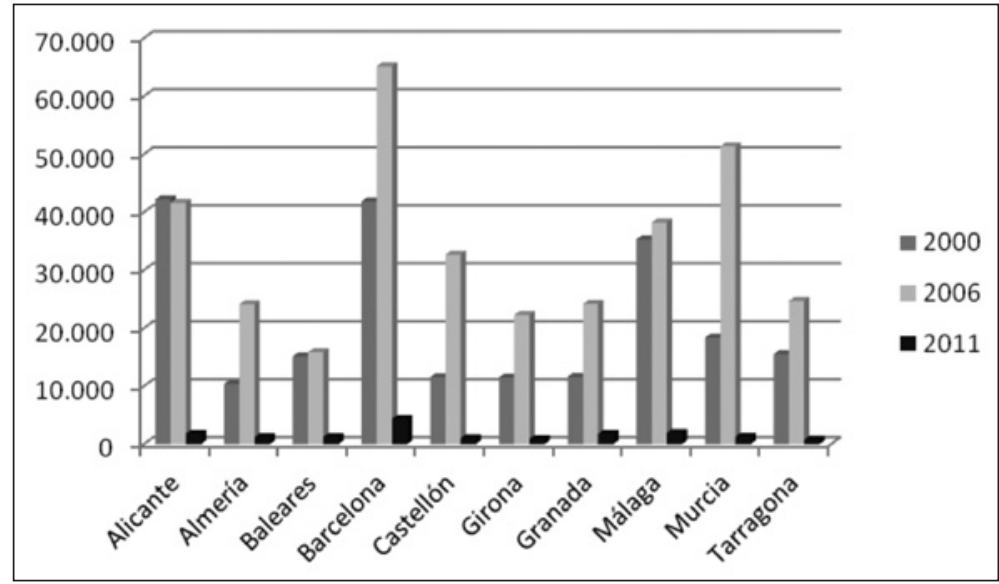

Fuente: Ministerio de Fomento. Elaboración propia.

La calidad de los sistemas de transporte, el precio del suelo, las preferencias individuales a la hora de elegir la tipología de la vivienda, las tendencias demográficas, las tradiciones y limitaciones culturales y el atractivo de las zonas urbanas existentes son factores que influyen en la forma en que se desarrolla un área urbana (EEA, 2006). La combinación de una serie de causas (socioeconómicas, culturales, sistemas de movilidad o normativas 
Tabla 1

$N^{\circ}$ DE VIVIENDAS VISADAS Y SUPERFICIE CONSTRUIDA (2000-2011) EN LAS PROVINCIAS ESPAÑOLAS CON LITORAL EN EL MAR MEDITERRÁNEO

\begin{tabular}{|l|r|r|r|r|r|}
\hline & $\begin{array}{c}\text { No viviendas } \\
\text { visadas }\end{array}$ & \multicolumn{1}{c|}{$\begin{array}{c}\text { superficie } \\
\text { construida }\left(\mathbf{m}^{2}\right)\end{array}$} & $\begin{array}{c}\text { Población } \\
\mathbf{2 0 1 1}\end{array}$ & $\begin{array}{c}\text { \% viviendas } \\
\text { visadas sobre } \\
\text { total nacional }\end{array}$ & $\begin{array}{c}\text { \% población } \\
\text { sobre total } \\
\text { nacional }\end{array}$ \\
\hline ESPAÑA & $\mathbf{5 . 6 6 8 . 0 4 7}$ & $\mathbf{9 3 1 . 7 5 8 . 6 4 7}$ & $\mathbf{4 7 . 2 1 2 . 9 9 0}$ & --- & -- \\
\hline Alicante & 345.410 & 50.995 .114 & 1.940 .956 & 6,09 & 4,11 \\
Almería & 154.513 & 22.047 .778 & 702.997 & 2,73 & 1,49 \\
Baleares & 118.069 & 20.493 .084 & 1.118 .654 & 2,08 & 2,37 \\
Barcelona & 405.086 & 67.519 .498 & 5.549 .224 & 7,15 & 11,75 \\
Castellón & 171.849 & 25.837 .479 & 604.358 & 3,03 & 1,28 \\
Girona & 132.727 & 15.702 .272 & 760.722 & 2,34 & 1,61 \\
Granada & 137.325 & 23.215 .599 & 920.151 & 2,42 & 1,95 \\
Málaga & 290.717 & 47.427 .613 & 1.639 .127 & 5,13 & 3,47 \\
Murcia & 292.708 & 48.724 .343 & 1.472 .837 & 5,16 & 3,12 \\
Tarragona & 164.235 & 24.990 .555 & 813.287 & 2,90 & 1,72 \\
Valencia & 274.623 & 48.363 .254 & 2.578 .197 & 4,85 & 5,46 \\
\hline \multicolumn{1}{|c|}{ total } & $\mathbf{2 . 4 8 7 . 2 6 2}$ & $\mathbf{3 9 5 . 3 1 6 . 5 8 9}$ & $\mathbf{1 8 . 1 0 0 . 5 1 0}$ & $\mathbf{4 8 , 3 3}$ & $\mathbf{3 8 . 3 3}$ \\
\hline
\end{tabular}

Fuente: Ministerio de Fomento e INE. Elaboración propia.

urbanísticas) ayudan a entender la magnitud de este fenómeno. En primer lugar, la aplicación de políticas de ordenación en el ámbito local y regional y, más concretamente, normativas que inciden en los usos del suelo y en el planeamiento urbanístico. En este sentido, hemos de hacer mención a la liberalización del proceso urbanizador experimentado con la aprobación de la Ley Reguladora de la Actividad Urbanística de la Comunidad Valenciana (1994), que agilizó los trámites para el desarrollo de actuaciones urbanísticas (Burriel, 2009). Significativo es, asimismo, la consideración del denominado «Suelo No Urbanizable»; aquel que, según el planeamiento territorial, «debe ser destinado a los usos propios de la naturaleza rústica de los terrenos» (Art. 1, Ley 10/2004, de 9 de diciembre, de la Generalitat Valenciana, del Suelo No Urbanizable). A pesar de las limitaciones, es en esta tipología de suelo donde la urbanización difusa se ha propagado a un ritmo vertiginoso en muchos municipios. La política de captación de ingresos por parte de los ayuntamientos a partir de las licencias de construcción y la revisión del planeamiento con el fin de crear suelo urbanizable se convirtieron en prácticas muy difundidas (Hernández, Moltó y Rico, 2008). Estas modificaciones legislativas y los ingresos económicos que generaron a las arcas municipales se tradujeron en un posicionamiento muy favorable, por parte de los gobiernos regionales, a un crecimiento urbanístico sin limitaciones en el que el carácter especulativo de las propuestas urbanísticas es otra característica de esta burbuja inmobiliaria (Romero et al., 2012). Relevante es, asimismo, el impulso de las infraestructuras y la mejora de las conexiones de transporte incentivadas por los Fondos de Cohesión y por los Fondos Estructurales de la Unión Europea. La reducción del tiempo empleado en los 
desplazamientos y la disminución de costes entre la residencia principal y la vacacional, entre el litoral mediterráneo español y el resto de Europa e, incluso, desde el interior peninsular hacia el litoral, ha facilitado el aumento de la movilidad. Dinámicas que se amplían hacia las áreas periurbanas y sectores próximos a los ejes de desarrollo urbano como ha sucedido, por ejemplo, entre el litoral de la provincia de Alicante o Málaga y su traspaís montañoso, configurándose una segunda e, incluso, una tercera «línea de costa».

Figura 2

EVOLUCIÓN DE LA POBLACIÓN EXTRANJERA (\%) EN LA FACHADA MEDITERRÁNEA ESPAÑOLA (2001-2011)

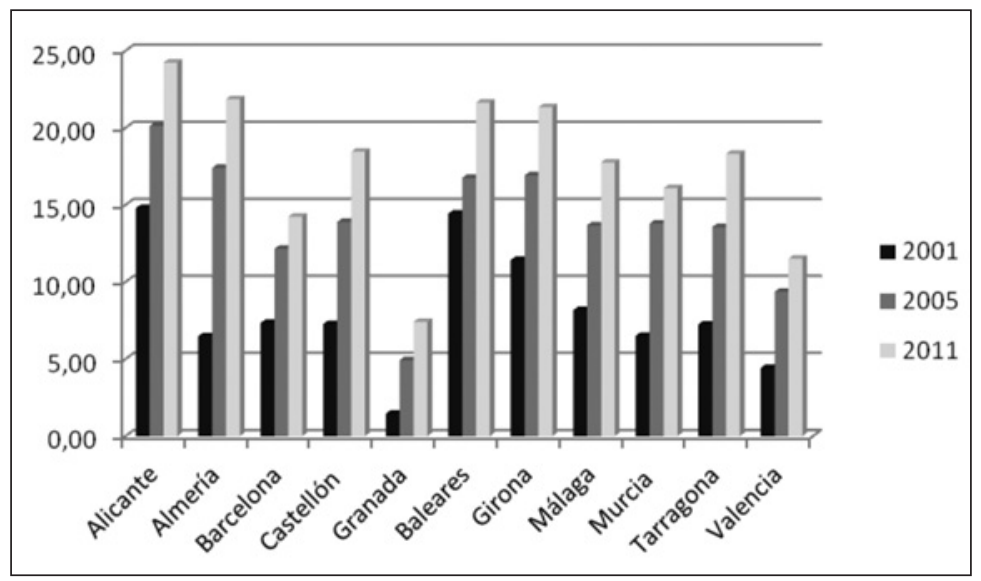

Fuente: INE. Elaboración propia.

El aumento en el parque de viviendas ha ido asociado al incremento demográfico. En el periodo comprendido entre 2001 y 2011, la población, según el Censo de habitantes, aumentó en unos 6,09 millones; alcanzando a finales de 2011 los 46,8 millones (INE, 2012). El factor explicativo de la expansión de las funciones residenciales en el litoral mediterráneo es la adquisición de viviendas por población procedente de otras regiones españolas; pero, sobre todo, por la fuerte demanda por parte de inmigrantes europeos, norteafricanos y sudamericanos. Según el Padrón de Habitantes, en el año 2000, el porcentaje de población extranjera ascendía al 4,5\% del total nacional, elevándose al 12,1\% en 2011 (INE, 2012); dato que adquiere una mayor magnitud en la escala regional y local (figura 2). Una mención diferenciada requiere el primero de estos colectivos y, concretamente, el integrado por población procedente del Centro y Norte de Europa, en el que predomina la población jubilada o prejubilada. En las provincias ribereñas del Mediterráneo, ésta se sitúa, salvo alguna excepción, en porcentajes alrededor del 15\% del total poblacional; alcanzando valores superiores al $50 \%$ en aquellas provincias en las que el desarrollo residencial (Baleares, Málaga y Alicante) se remonta a la década de los años setenta del siglo XX (figura 3). La provincia de Alicante es la única que, sin embargo, ha visto reducir levemente (menos de un $2 \%$ entre 2001 y 2011) la presencia de extranjeros europeos sobre el total de extranjeros. Esta aminoración no se debe a que haya disminuido su llegada que ha continuado siendo muy intensa, sino que junto a ésta se produce un importante incre- 
mento de emigrantes no europeos atraídos por una amplia oferta de trabajo vinculado al sector agrícola, a los servicios y a la construcción. El análisis en la escala local refleja la intensidad de la llegada de población europea en la última década. Llamativos resultan municipios como Rojales, San Fulgencio o San Miguel de Salinas (sur de la provincia de Alicante) en los que el porcentaje de extranjeros ha pasado del 35 al $70 \%$ del total poblacional entre 2001 y 2011, respectivamente; ocupando los primeros puestos del ranking de municipios españoles con mayor número de extranjeros. En municipios, con desarrollos residenciales más antiguos, como Alfaz del Pí, Calpe (norte de la provincia de Alicante) o Torrevieja, el incremento ha sido menor, si bien también es el colectivo mayoritario: la población extranjera ya alcanzaba porcentajes en torno al $50 \%$ del total poblacional en 2001 y ésta se ha incrementado en un $10 \%$ en el último intercensal.

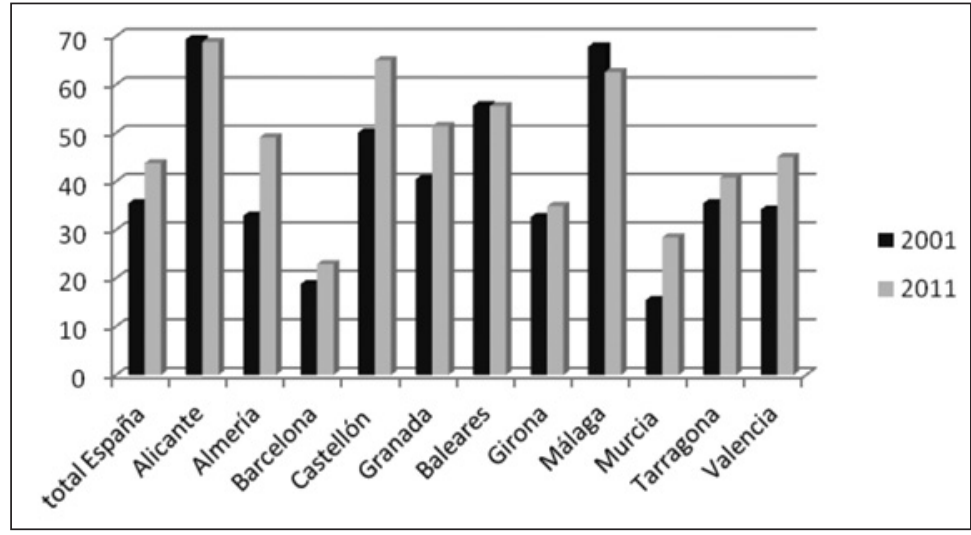

Fuente: INE. Elaboración propia.

Se trata de un grupo poblacional en aumento constante durante los últimos años, que encuentra en las condiciones climáticas de las tierras del mediterráneo español la justificación principal para la compra de viviendas. En efecto, junto a la accesibilidad, la tranquilidad o el atractivo paisajístico, los adquirientes extranjeros valoran especialmente la elevada insolación, con valores medios que en la Comunidad Valenciana y, en general, en el litoral mediterráneo español, superan las 2.700 horas, y un régimen térmico templado de filiación mediterránea, que resulta mucho más confortable que el existente en sus países de origen. También, el precio de las viviendas justifica su adquisición. En la denominada «segunda línea de costa» resulta bastante menor al que rige en los municipios costeros y, además, a costes muy asequibles en contraste con los existentes en ciudades de Europa occidental. El precio medio de la vivienda en el territorio valenciano ha experimentado, como en el resto del territorio nacional, un crecimiento hasta el estallido de la crisis inmobiliaria en 2008. Se ha pasado de $525 €$ en 1993 a unos $1.600 €$ en 2009. Año a partir del cual inicia un descenso hasta situarse en $1.467 €$ en 2011 (Conselleria de Vivienda, 2012) y, en torno, a unos 1.000 $€$ en los municipios litorales a principios de 2013 . 
El análisis de la evolución del número de visados de obra nueva para uso residencial (figura 4) refleja, la magnitud del boom de la construcción y el estallido de la crisis inmobiliaria a partir de 2008, cuando la construcción de nuevos edificios se ha reducido drásticamente. Basta comparar los 227.142 visados de 2005, frente a los pocos más de 23.000 en 2011. Pero, también pone de manifiesto la tipología urbana dominante. La expansión residencial ha ido acompañada de una intensificación en el cambio de modelo urbano iniciado a mediados de la década de los años ochenta del pasado siglo. Frente al concentrado y en altura caracterizado por construcciones en bloque (apartamentos), la expansión residencial se ha fundamentado en la difusión de nuevos modelos urbano-residenciales de media y baja densidad basados en la proliferación de unifamiliares adosadas y viviendas unifamiliares en zonas periurbanas, cuando no en entornos no urbanos hasta entonces, donde los usos exteriores de las viviendas (jardines y piscinas privadas) son uno de sus elementos definidores. La tipología «viviendas unifamiliares» en la provincia de Alicante ha registrado una evolución similar a la experimentada en el estado español: el porcentaje sobre el total de las nuevas viviendas se sitúa por encima del $35 \%$ entre 2000 y 2005 ; iniciándose un ligero retroceso a partir de esa fecha hasta situarse en valores medios del $25 \%$ desde 2006 hasta la actualidad. En cualquier caso y como sucede en el resto de tipologías, el hecho clave es la drástica reducción en el proceso de visado de viviendas.

$N^{\circ}$ DE VISADOS DE OBRA NUEVA PARA USO RESIDENCIAL EN ESPAÑA (2000-2011)

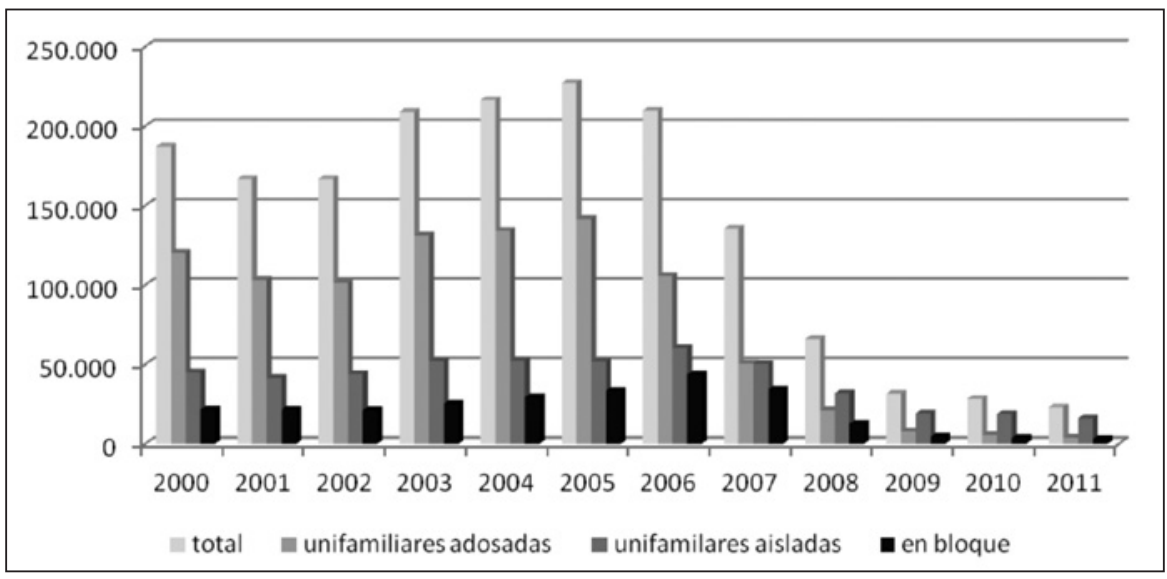

Fuente: Ministerio de Fomento. Elaboración propia.

\section{OBJETIVOS Y METODOLOGÍA}

La expansión residencial junto con el incremento de los modelos urbanos más extensivos ha significado un aumento significativo de áreas verdes tanto públicas como privadas. Éste se vincula a un doble proceso. Por un lado, la adecuación y ajardinamiento de los nuevos espacios urbanizados, generalmente viales de acceso y calles, tanto por entes públicos (ayuntamientos) como privados (promotoras urbanas). Por otro, la existencia de 
zonas verdes comunes en las urbanizaciones o de jardines privados en el caso de chalets unifamiliares. En ambos, estas tipologías se asocian a modelos urbanos más extensivos frente a los más concentrados y característicos de ámbitos semiáridos. Además, elementos externos como jardines y piscinas adquieren una elevada presencia en estos nuevos espacios urbanos. Son estas áreas verdes y no los jardines públicos el objeto de análisis en esta publicación.

A la hora de abordar las repercusiones territoriales y ambientales derivadas de esta expansión residencial, un tema que ha recibido una notable atención por diversos colectivos científicos ha sido el que analiza las relaciones entre urbanización y demandas hídricas. En éste, un aspecto clave a tener en cuenta es que no existe uno, sino muchos procesos de urbanización y que cada uno de ellos conlleva una demanda y un comportamiento diferente en relación a los insumos necesarios para su funcionamiento. El consumo de agua en zonas urbanas de baja densidad, por ejemplo, es manifiestamente superior al de áreas de alta densidad por la presencia de usos exteriores como jardines y piscinas (Rico, 2002). Por tanto, poner de manifiesto las relaciones que se establecen entre la expansión urbano-residencial registrada en la última década y su incidencia en los consumos de agua resulta prioritario en países como España, donde el urbanismo de baja densidad se caracteriza por una tendencia creciente. Las relaciones entre el incremento de tipologías urbanas extensivas en las que los espacios ajardinados (a pesar de las notables diferencias en superficie) son un elemento definidor y el aumento de la demanda de plantas ornamentales no han recibido demasiada atención hasta ahora. A priori, estas relaciones parecen evidentes; pero es necesario explicitarlas y analizar sus consecuencias desde el punto de vista económico-productivo. El perfil socio-demográfico de los nuevos habitantes, en el caso del litoral de Alicante, con elevada presencia de población centroeuropea, procedente de medios más fríos y húmedos y con modelos urbanos más extensivos puede ser un factor que contribuya a la difusión de esos modelos extensivos, pero también puede condicionar la tipología de plantas dominantes en ellos. Explorar las relaciones que se establece entre expansión residencial e inmigración europea puede proporcionar variables sociales (edad, nivel de renta, cultura, etc.) que expliquen la expansión de estas superficies e, indirectamente, los consumos hídricos.

Teniendo en cuenta ambos elementos (modelos de urbanización y factores que inciden en las pautas de consumo), los objetivos específicos de este artículo son:

- Comprobar la difusión de los espacios ajardinados y el boom de la construcción y la expansión de las empresas destinadas a la planta ornamental (producción y comercialización),

- Analizar una posible correlación entre la difusión de áreas verdes asociadas a la expansión de los usos urbano-residenciales y su impronta en el sector de la planta ornamental como actividad de alta capacidad de generar renta y de demanda de mano de obra por unidad de superficie.

A tenor de los objetivos descritos, en esta publicación se analizan espacios ajardinados generalmente privados asociados a la tipología urbana de chalets unifamiliares, así como los comunitarios existente en la de bloques de apartamentos y adosados. Se obvian, en cambio, los jardines públicos. Consiguientemente, cuando se emplee el término espacio o área verde o jardín nos 
referiremos a los espacios privados, a los usos externos de las viviendas y de las urbanizaciones asociados a modelos urbanos más extensivos y excluyendo, por tanto, los jardines públicos.

A nivel metodológico, el artículo adopta un enfoque integrado por el cual se combinan primeras (análisis estadístico de bases de datos) con metodologías cualitativas (entrevistas). Por lo que se refiere a las metodologías cuantitativas, éstas se centran en cuatro aspectos básicos: 1) Análisis de la evolución del número de viviendas y de visados de fin de obra entre 2000 y 2011; 2) Examen de la evolución de superficies ocupadas por planta ornamental y de las especies mayoritarias entre 2000 y 2011; 3) Análisis cronológico del número de establecimientos vinculados a la venta de productos para jardines, los denominados garden centers; y 4) Rentabilidad económica y social del cultivo y comercialización de la planta ornamental. La consulta y manejo de estas fuentes documentales primarias permite establecer las características de la expansión residencial (intensidad del proceso, áreas con mayor o menor afectación, superficie urbanizada, tipologías de edificación, etc.) y de las repercusiones sobre la población (aumento de la población extranjera); pero también, la evolución experimentada por el cultivo y la comercialización de plantas ornamentales y su relación con la difusión de tipologías urbanas más extensivas. La metodología cualitativa se ha basado en: 1) Entrevistas con una treintena de empresarios agrícolas y propietarios de explotaciones de planta ornamental para conocer la dinámica del sector. La selección del número de entrevistados abarcó a las diferentes tipologías de explotaciones agrícolas identificadas en el área de estudio. Para ello con anterioridad, se definieron los tipo de explotación existente basándose en tamaño, plantas dominantes y sistema de gestión; 2) entrevistas con asociaciones de productores y exportadores de planta ornamental; 3) entrevistas a una veintena de propietarios de garden center. Al igual que en el caso de los empresarios agrícolas se identificó las principales tipologías existentes en el área de estudio atendiendo a criterios como finalidad (comercialización o producción y comercialización), tamaño, año de apertura y servicios prestados. La información obtenida ha permitido identificar las dinámicas registradas por el sector incorporando aspectos cualitativos entre los que cabe citar, por ejemplo, los factores tanto estructurales como coyunturales que incidieron en la intensificación del cultivo de ornamentales. Su comparación con los datos aportados por las estadísticas permite evidenciar las tendencias no sólo cuantitativas, sino también los factores desencadenantes de éstas y las expectativas de futuro que productores y propietarios de garden tienen respecto a esta actividad económica; especialmente teniendo en cuenta la importante reducción de la demanda. Cuestión esta importante, dada la importante vinculación de las empresas productoras de planta ornamental con el sector de la construcción. Por último, permitió completar y corroborar el grado de fiabilidad de la información estadística.

La metodología descrita pretende reflexionar sobre los objetivos citados y, sobre todo, analizar las repercusiones territoriales y socio-económicas vinculadas a la difusión del cultivo de planta ornamental y de los garden center en un ámbito territorial concreto, a modo de caso de estudio. El área elegida, los municipios litorales y prelitorales de la provincia de Alicante, se argumenta en una serie de factores:

- Es un territorio donde la urbanización ha sido muy intensa a partir del desarrollo del turismo en las décadas de 1960-70 y que se ha acentuado en la primera década del siglo veintiuno. 
- El proceso urbanizador ha ido asociado a la difusión de modelos urbanos más extensivos, donde la presencia de jardines y piscinas son elementos característicos y, en ocasiones, omnipresentes.

- Esta dinámica presenta una implantación diferenciada tanto en el tiempo como en su intensidad y tipología urbana entre los municipios más septentrionales y los meridionales. Rasgos que condicionan la mayor o menor difusión de áreas ajardinadas y la presencia de garden center.

- La intensidad del proceso de expansión urbana se asocia a la llegada de importantes volúmenes de población extranjera procedente del Centro y Norte de Europa.

- La presencia de actividades agrícolas intensivas y de rentabilidad media-alta, en las que los cultivos hortícolas tempranos o extra-tempranos, flores y planta ornamental tienen trascendencia territorial, social y económica.

\section{EL SECTOR DE LA PLANTA ORNAMENTAL EN ALICANTE: CRECIMIENTO, CRISIS Y RES- TRUCTURACIÓN}

La expansión residencial y, más concretamente, la trascendencia adquirida por los elementos externos (jardines y piscinas) ha generado repercusiones desde el punto de vista paisajístico y territorial, que han sido analizadas de manera profusa en la última década y desde colectivos científicos diversos (Hernández, 2013). Las consecuencias vinculadas al consumo de agua de los diferentes componentes urbanos, los elementos que inciden en la elección de una tipología urbana u otra o las potenciales influencias e interrelaciones con las actividades económicas existentes han merecido una menor atención por parte de la comunidad científica.

Nuestra hipótesis de trabajo sostiene que en los nuevos modelos urbanos más extensivos, las plantas ornamentales constituyen agentes activos en la creación de nuevas naturalezas urbanas muy vinculadas a las tipologías residenciales dominantes. Poner de manifiesto las interrelaciones que se establecen entre el incremento de la superficie ocupada por las plantas ornamentales y el número de centros de venta y la expansión de los usos urbano-residenciales en el litoral mediterráneo y, especialmente, en aquellos modelos de densidades medias o bajas es un elemento esencial a la hora de caracterizar y definir estas nuevas naturalezas urbanas.

\section{III.1. Evolución de la superficie y de la producción de planta ornamental}

El análisis de la dinámica y de las características que definen a los aprovechamientos agrícolas es una temática de honda tradición por parte, entre otros colectivos, de los geógrafos adscritos a la línea de investigación de Geografía Rural. En ella, la evolución de las superficies cultivadas y específicamente de las regadas, los cambios registrados por los principales cultivos, la incidencia de las políticas agrarias y de mercado o las repercusiones sociales y económicas asociados a esta práctica son temáticas que han recibido una particular atención. El escaso número de publicaciones relativas al cultivo de flores y planta ornamental se debe en gran medida a dos hechos: su menor impacto paisajístico en comparación con otros cultivos, dada su reducida superficie cultivada a nivel nacional (unas 6.000 hectáreas 
en 2010, según el Ministerio de Agricultura) y la existencia de ciertos procesos que contribuyen a encubrir su presencia. Entre ellos, cabe citar que un porcentaje significativo de estos cultivos se hacen bajo protección de invernadero y forman parte de los grandes conjuntos de paisajes bajo plástico que han sido analizados desde la perspectiva de las producciones hortofrutícolas. Conforman, no obstante, un modelo productivo de alta rentabilidad, similar al existente en la margen septentrional del valle del Arno, entre Luca y Pistoia (Italia), una de las áreas de mayor producción de planta ornamental de Europa, con unas 5.000 ha. Concentración que, en el área de estudio (provincia de Alicante), se localiza en el sector norte de la comarca de la Vega Baja, en su contacto con la Sierra de Crevillente, entre Albatera y Torrellano (Elche).

Estos aprovechamientos, sin embargo, tienen una gran trascendencia social y económica De la primera, hay que destacar el alto grado de ocupación de mano de obra implicada en su proceso productivo (Naredo, 1996), cifrado entre 5 y 6 UTAs por hectárea y año, de media. Estos valores contrastan con la generación de empleo de otros cultivos hortícolas y frutícolas intensivos (agrios) o extensivos (viñedo, olivar o cereales), que oscila entre las $0,08 \mathrm{Uta} / \mathrm{ha}$ de los cereales y las 0,4 de los cítricos (Morales, 1997: 150; Hernández y Morales, 2009). Estos datos adquieren su trascendencia social, si trasformamos estos valores en mano de obra. Las 1.609 hectáreas de plantas ornamentales cultivadas en la Comunidad Valenciana en 2011 generaron unos 8.850 empleos a jornada completa. Las 69.111 hectáreas ocupadas por el viñedo de vinificación $(0,15 \mathrm{Uta} / \mathrm{ha})$ dieron ocupación a unos 10.350 empleados, es decir, el 2,3\% de la superficie del viñedo precisa la misma mano de obra que la de flores y planta ornamental. La misma superficie de viñedo que toda la de ornamentales únicamente precisaría unos 240 empleados/año. Acentuando ese valor social, habría que resaltar que los empleos que genera, en un gran porcentaje (70 u 80\%), se pueden considerar como estables durante prácticamente todo el año; rompiendo con la tendencia del trabajo eventual que presentan los cultivos de secano y de algunos regadíos intensivos, como pueden ser los cítricos. Estos factores son los que inciden, además, en la estabilidad y consolidación de estructuras urbanas que se han desarrollado en algunas de las poblaciones próximas en los últimos veinte años, frente al éxodo rural que los caracterizaba en los años 60 y 70 (Hernández y Morales, 2008). Muchas de estas explotaciones tienen un carácter familiar, donde suelen emplearse los padres y, a veces, el resto de la unidad familiar (hijos). Éstos últimos se han consolidado como trabajadores de la explotación agrícola a partir de 2007, cuando la crisis económica de otros sectores productivos, fundamentalmente, el de servicios y la construcción, ha expulsado abundante mano de obra, que, en gran medida, ha sido captada por la agricultura intensiva de regadío, sobre todo, la de ciclo manipulado, entre las que se encuentran las flores y las plantas ornamentales.

Asimismo, hay que hacer mención a su rentabilidad económica. El valor de la producción de los cultivos hortícolas, flores y plantas ornamentales en 2011 ascendió a 6.669,1 millones de euros (MAGRAMA, 2012a), es decir, el 27,5\% del valor de la producción vegetal frente al 3,9\%, por ejemplo, del vino. Rentabilidad que se eleva si tenemos en cuenta varios factores. Primero, la superficie ocupada por cultivos hortícolas y flores asciende a unas 202.453 hectáreas frente a las 972.085 del viñedo para vinificación. En segundo lugar, el valor de la producción del epígrafe «hortalizas, flores y planta ornamental» se concentra en una serie de producciones específicas como son las hortalizas de primor, las flores y las ornamentales. 
Su trascendencia económica se incrementa al considerar su aportación al PIB. Frente al valor negativo de la balanza comercial española en su conjunto, el sector de «plantas vivas y productos de floricultura» presenta un balance positivo (ICEX, 2011). Tendencia que se ha ido incrementando y consolidando en la última década (figura 5). Sin alcanzar el monto y la trascendencia de los cultivos hortícolas, las plantas ornamentales se configuran en ciertos territorios, entre los cuales, se encuentra la Comunidad Valenciana y la provincia de Alicante, en particular, como una opción para mantener superficies cultivadas y activos agrarios frente a aprovechamientos de baja rentabilidad y subvencionados. Valor positivo que se mantiene en la actual coyuntura de crisis. La Federación Española de Productores y Exportadores de Frutas, Hortalizas y Plantas Vivas (FEPEX) ha señalado en su informe anual, que «las exportaciones españolas de flor cortada se han incrementado un 4\% en 2011» (FEPEX, 2012). Ese aumento ha sido mayor en la Comunidad Valenciana que ha visto como el valor de las exportaciones de este epígrafe prácticamente dobló su valor al pasar de unos 36,7 millones en 2002 a 60 en 2011 (IVEX, 2012).

Figura 5

EVOLUCIÓN DE LAS IMPORTACIONES Y EXPORTACIONES DE PLANTAS VIVAS Y FLORICULTURA (EN MILES DE €) EN ESPAÑA

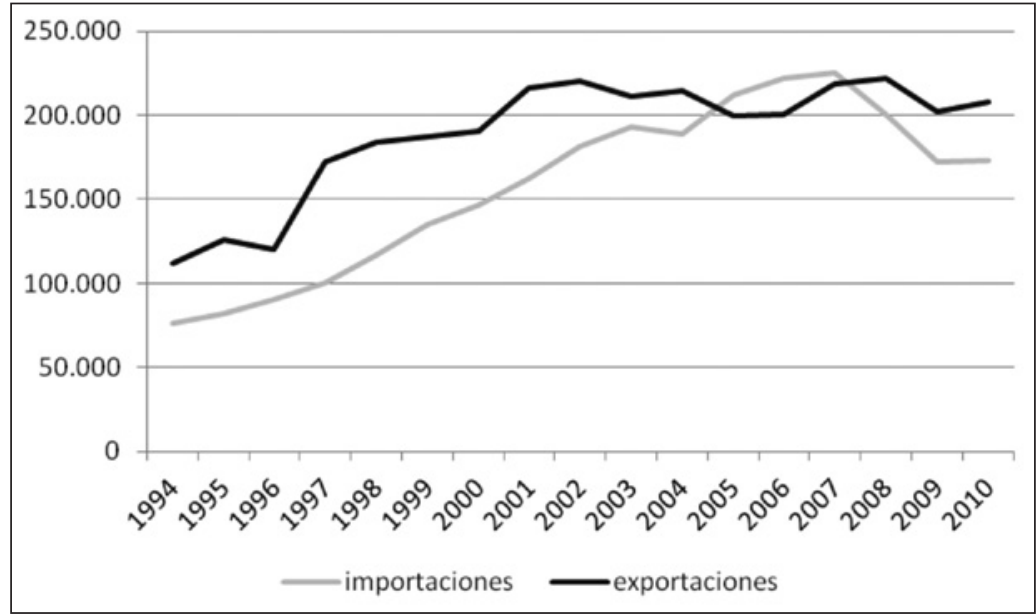

Fuente: IVEX. Elaboración propia.

Estos rasgos, sin embargo, se asocian con dos tipologías de paisajes diversas y contrastadas. Los cultivos de flor cortada se vinculan a invernaderos, mientras que los de ornamentales se practican al aire libre, en viveros de palmeras y olivos, que posteriormente son trasplantados. Estos últimos, a cierta distancia, recuerdan a los paisajes tradicionales de estas tierras. Una segunda diferencia se relaciona con sus requerimientos hídricos. Los de flor cortada precisan unas dotaciones elevadas, alrededor de los $10.000 \mathrm{~m}^{3} /$ año. Volúmenes que contrastan con los de los viveros de palmeras, olivos y arbustos mediterráneos que reciben uno o dos riegos al año con una dotación media entre 2 y $3.000 \mathrm{~m}^{3} /$ año. Consumos que, al igual que sucede con las demandas de mano de obra, generan una elevada rentabilidad eco- 
nómica por $\mathrm{m}^{3}$ de agua consumida. La productividad bruta de un cultivo de cereal se situaría entre 0,12 y $0,18 € / \mathrm{m}^{3}$ frente a los 0,55 de los cítricos y 0,80 de los hortícolas al aire libre; elevándose ésta a unos 3 euros en el caso de aprovechamientos en invernadero (Melgarejo, Martínez y Martínez, 2004).

En la última década, la tendencia muestra una clara dinámica alcista a escala nacional: en menos de 15 años se ha duplicado la superficie, que ha pasado de unas 2.000 hectáreas en 1997 a unas 5.100 en el año 2010; incrementándose, asimismo, el peso que estos cultivos tienen sobre el total del epígrafe de «flores y plantas ornamentales». En 1997, la superficie ocupada por plantas ornamentales representaba el $43 \%$ del total del epígrafe flores y plantas ornamentales, incrementándose hasta el 75\% en 2011 (MAGRAMA, 2012a). Factores como la creación y ornamentación de nuevas áreas urbanas que inciden en la demanda de planta ornamental y su mayor rentabilidad frente a cultivos de flores como los claveles justifica ese aumento y su difusión en áreas con una escasa implantación. Elementos a los que debemos unir la relación existente entre nivel de desarrollo económico y el consumo de plantas ornamentales: a mayor nivel de renta en un país, mayor demanda de estos productos (Albardiaz, 1998).

La Comunidad Valenciana ha visto, a pesar del incremento en datos absolutos, aminorado su peso porcentual en los últimos quince años. De concentrar más del 50\% del total nacional en 1997, ha visto reducido ese porcentaje en más de veinte puntos en 2010, además, de verse superada por la Comunidad Autónoma de Cataluña como principal área por superficie, que ha duplicada ésta entre 2008 y 2010 (figura 6). Ambas regiones reúnen el 66\% del total nacional de la superficie ocupada por este aprovechamiento. Un análisis a escala provincial evidencia una dinámica opuesta entre las dos principales áreas productoras de la región valenciana (figura 7). La provincia de Alicante experimenta un notable incremento entre el año 2000 y el 2006 (auspiciado en gran medida por la demanda vinculada al ajardinamiento de las nuevas áreas urbanas) y una disminución significativa a partir de 2007. La plaga del picudo rojo que afecta a las palmeras puede explicar, unido a la propia caída de la demanda vinculada a la construcción, una dinámica negativa, si bien perduran los viveros con pocos cuidados, pero destinando parte de ellos a la palmera blanca (equivalente a flor cortada) para celebraciones religiosas cristianas, judías y musulmanas. Una tendencia alcista registra la provincia de Valencia, que mantiene una evolución sostenida hasta 2007, para experimentar un notable incremento a partir de esta fecha, relacionado en gran medida con una destacada orientación a la exportación. Su crecimiento compensa la pérdida de superficies en la provincia de Alicante y contribuye a la tendencia positiva de la región.

La evolución de la superficie y de los principales aprovechamientos en el área de estudio (provincia de Alicante) refleja los factores generales, ya citados, pero, especialmente, la fuerte dependencia con el sector de la urbanización y promoción urbana. La crisis económica de los últimos cinco años se ha dejado sentir, también, en la producción de plantas ornamentales y flor cortada. A la primera, le ha afectado la retracción de la actividad constructiva de urbanizaciones y nuevos barrios en las ciudades, junto a la disminución de disponibilidades económicas que las administraciones locales han registrado en los últimos años y que han dado al traste con los procesos de remodelación de barrios y zonas ajardinadas. A la segunda, además, de la disminución de la demanda de flor cortada por el menor poder adquisitivo de las sociedades a las que iban destinadas sus producciones, le ha perjudicado la incidencia 
Figura 6

EVOLUCIÓN DE LA SUPERFICIE OCUPADA POR ORNAMENTALES (HA)

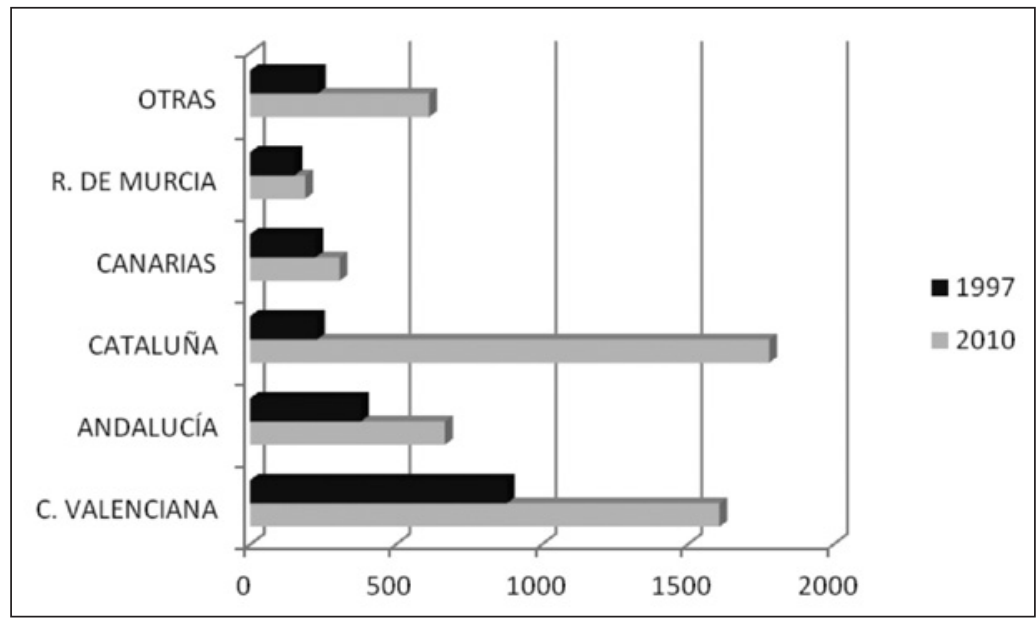

Fuente: Ministerio de Agricultura. Elaboración propia.

Figura 7

EVOLUCIÓN SUPERFICIES EN LA COMUNIDAD VALENCIANA (HA)

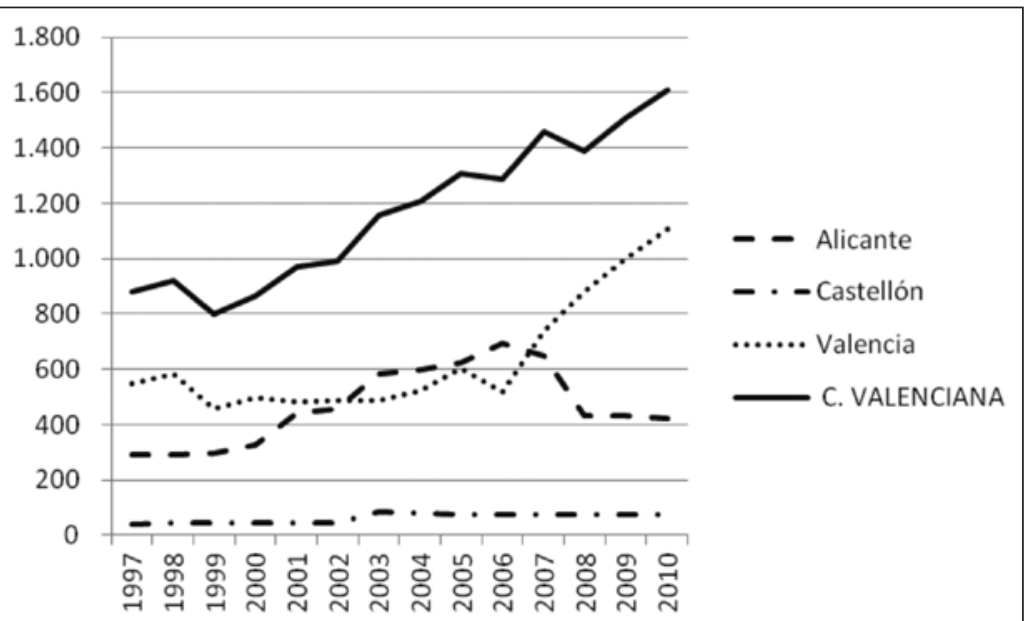

Fuente: Ministerio de Agricultura. Elaboración propia.

de las importaciones procedentes de terceros países ubicados en tierras intertropicales, básicamente, casos de Colombia, Sureste asiático, ... que, con costes de producción más bajos, pueden perfectamente acudir a los mercados de la UE mediante un transporte aéreo desde el lugar de origen hasta el de consumo. Provocando, consiguientemente, una caída de precios que han hecho inviables, por ejemplo, los cultivos de claveles, rosas, gerberas, etc. 
El análisis de las áreas productoras en la provincia de Alicante (figura 8) evidencia una marcada concentración territorial en el sur de esta provincia (comarcas de la Vega Baja y Campo de Elche). Este proceso se relaciona con la importancia que la agricultura intensiva (aprovechamientos hortícolas con predominio de cultivos de primor y en invernadero) tiene en este ámbito territorial. La marcada orientación al mercado y la especialización productiva que caracteriza desde finales de la década de 1980 a los aprovechamientos hortofrutícolas y, más concretamente, a la horticultura de primor, como estrategia para mantener su rentabilidad y, de este modo, hacer frente al incremento de costes y competir con la expansión de los usos turístico-residenciales posibilita la difusión de flores y ornamentales. Su elevada rentabilidad justifica la elección de este tipo de aprovechamiento frente a otros de menor capacidad para generar rentas. El sur de la provincia de Alicante se afianza como la principal área productora al reunir alrededor del $90 \%$ de la superficie del área de estudio, que a su vez se concentra en los municipios de Elche, Albatera y Pilar de la Horadada, donde se localiza la práctica totalidad de los invernaderos con tecnología de alta vanguardia y alrededor de un 35\% de la superficie nacional en 2011 (MAGRAMA, 2012a). Otro rasgo que los caracteriza es la fuerte dinámica que los define: son los aprovechamientos que porcentualmente registran un mayor incremento. Las superficies totales resultan reducidas, sin embargo, su capacidad para generar rentas y empleo, los convierten en uno de los cultivos más sociales de estas comarcas.

Figura 8

EVOLUCIÓN DE LAS SUPERFICIES (HECTÁREAS) DESTINADAS A PLANTAS ORNAMENTALES (1999-2011)

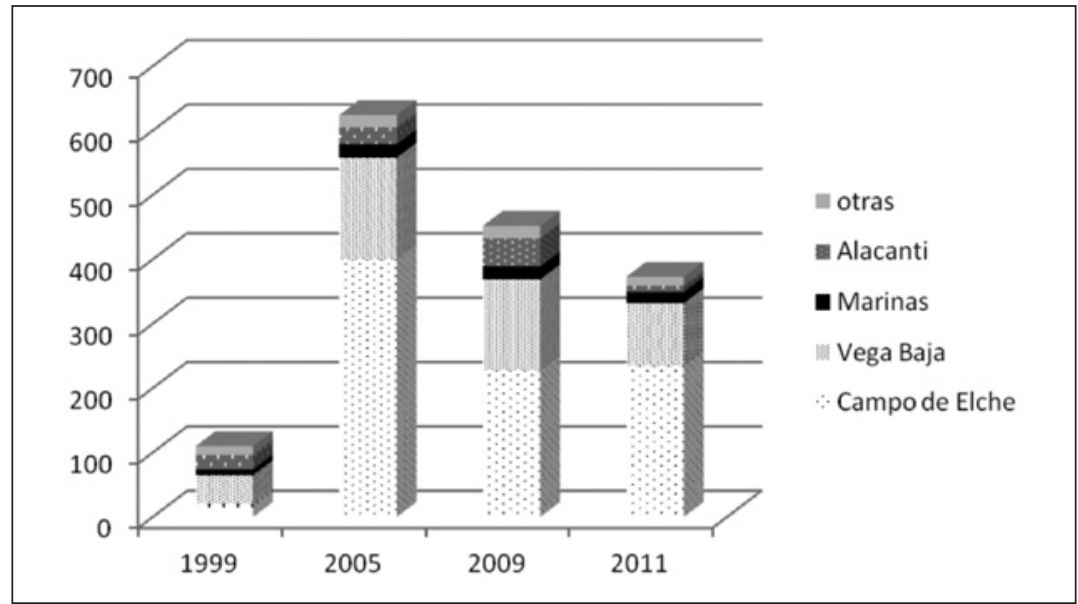

Fuente: Conselleria de Agricultura (Generalitat Valenciana) y MAGRAMA Elaboración propia.

Además, de la marcada concentración territorial, los atributos que definen a este tipo de explotaciones se relacionan con su tamaño y sistema de gestión, técnicas de cultivo, aprovechamientos practicados y canales de comercialización. Existen dos líneas básicas de cultivo, a saber, «plantas y pequeños arbustos» $\mathrm{y}$ «cultivos de arbustos de gran porte y árboles». La primera engloba aprovechamientos como: plantas de temporada y anuales, de 
interior y vivaces y plantas aromáticas y pequeños arbustos. La segunda incluye a palmáceas, coníferas, olivos, etc. Esta distinción si bien no puede aceptarse como un axioma, ya que hay explotaciones que practican ambas, si se observa una cierta especialización que determina algunos rasgos particulares de las explotaciones como es su tamaño y técnicas de cultivo. Las condiciones climáticas de estos territorios permiten el cultivo de una gran variedad de especies tanto de interior como de exterior; de esta forma, es usual encontrar viveros que además de plantas en invernadero, presentan grandes extensiones al aire libre para el desarrollo de arbustos y arbolado. El tamaño de medio de la explotación se sitúa en torno a las 7 hectáreas, correspondiendo a unidades productivas entre las 2 y las 7 ha. a aquellas especializadas en «plantas y pequeños arbustos» y con valores superiores a la media, las centradas en «arbustos y árboles» (entre las 3 y las 18 hectáreas). La utilización de sistemas de cultivo en invernadero es elevado; si bien los porcentajes más altos se obtienen en la línea de plantas y pequeños arbustos con valores medios entorno al 40-50\% del total de la explotación, donde las necesidades de mayor aporte calórico a las plantas de temporada o anuales conlleva la presencia de este sistema. En cambio, éste no suele superar el 10\% en «cultivos de arbustos de gran porte y árboles», donde la superficie al aire libre es dominante, ya que las variedades practicadas no requieren aportes térmicos extra. Los viveros de palmeras y olivos al aire libre son los aprovechamientos mayoritarios en la provincia de Alicante.

El punto fuerte de la actividad estriba en su versatilidad con respecto a la producción. Es posible cambiar de cultivo y, por tanto, poder orientar la oferta hacia otro segmento de clientes, sin que ello suponga una alteración importante en las estructuras de la empresa. No obstante, la duración del ciclo de cultivo determina una mayor o menor adaptabilidad a los cambios en la demanda. Éste se sitúa en torno a un año en el caso de «plantas y pequeños arbustos» frente a valores que oscilan entre 2 y 8 años para grandes arbustos y árboles. Ello determina que hayan sido las explotaciones en las que predominan éstos últimos, las más afectadas por la crisis inmobiliaria. Las variedades dominantes (palmáceas y olivos) tienen una nítida vinculación con la adecuación de zonas verdes, muchas de ellas de carácter público. Áreas en las que es frecuente también la presencia de un tapiz de césped que proporciona el carácter verde a un espacio en el que se inserta un segundo nivel ornamental integrado por flores, arbustos o árboles. El césped es un elemento altamente valorado por la población de ámbitos semiáridos al proporcionar unas tonalidades cromáticas que contratan con las tonalidades ocres dominantes, asociadas a estos climas. Éste es proporcionado por un número reducido de empresas especializadas que lo adquieren fuera del área de estudio y lo instalan.

Los principales clientes corresponden a los centros de jardinería no productores (garden center), instituciones públicas (ayuntamientos y diputaciones), mayoristas (hipermercados y centros comerciales), minoristas (floristerías) y público en general. Establecer porcentajes en lo referente a la segmentación de la clientela es difícil. Cada empresa tiene su tipología de clientes y sus mercados, condicionados en muchas ocasiones por el producto cultivado, variando ostensiblemente unas de otras. No obstante, y en conjunto, podríamos establecer la siguiente distribución: empresas de jardinería (45\%), mayoristas (31\%), comercio minorista y público (14\%) e instituciones públicas (9\%). Es necesario, no obstante, distinguir entre productores especializados en «plantas y pequeños arbustos» y «grandes arbustos y árboles». En los primeros, la cartera de clientes se articula alrededor de los centros de jardinería 
no productores, minoristas y público en general. Éste último con una tendencia creciente, especialmente, en el sector sur de la provincia donde se concentran las explotaciones. La comercialización directa, especialmente la que se orienta al público en general, se ha ido incrementado en los últimos años, cuando algunos productores han contemplado esta opción como una medida para incrementar la rentabilidad de su explotación. La existencia de un gran número de productores diseminados por las comarcas meridionales de la provincia de Alicante (Vega Baja y Bajo Vinalopó) facilita la compra por parte de clientes que proceden de la misma ciudad o núcleos urbanos próximos sin necesidad de recorrer grandes distancias. En la cartera de grandes arbustos y árboles, han sido las administraciones públicas y los mayoristas los grandes demandantes. El segmento «público en general» ha visto incrementado significativo su número, pero su porcentaje en el total de las ventas sigue siendo minoritario (menos del 5\%).

La evolución de las superficies ocupadas por flores y plantas ornamentales refleja esa creciente especialización. Las 147 hectáreas de 1998 ascienden a unas 1.757 en 2011 (MAGRAMA, 2012a). El incremento entre 1999 y 2005, cuando se alcanza la mayor superficie cultivada, resulta francamente espectacular. La coincidencia con el periodo álgido de la adecuación urbana de los nuevos espacios urbanizados tanto públicos como privados resulta indudable. Esta dinámica alcista se relaciona con la fuerte demanda realizada por ayuntamientos y promotoras y, en menor medida, por particulares. Ayuntamientos y promotoras adquieren determinadas especies, mayoritariamente palmeras (variedades Chamaerops Humilis, Washingtonia Robusta, Phoenix Canariensis, Phoenix Dactylifera y Chamaerops Excelsa) y olivos (Olea Europea) para acondicionar los espacios públicos (viales, rotondas o áreas ajardinadas) de las nuevas áreas urbanizadas. Ésta se complementa con la realizada por los particulares que adquieren para ornamentar los exteriores de sus nuevas viviendas. El notable aumento de las tipologías urbanísticas en las que predominan las áreas ajardinadas (chalets unifamiliares y adosados en promociones comunitarias) contribuye a incrementar el consumo de plantas ornamentales. Por tanto, el aumento de la demanda de planta ornamental y su alta rentabilidad explicarían este incremento. La expansión de los usos urbanoresidenciales adquiere una repercusión nítida en los ingresos de los ayuntamientos. Si bien, la casuística es variada, dependiendo en gran medida de indicadores como la intensidad del proceso, el tamaño del municipio y las actividades económicas de éste, entre otras, estos ingresos municipales experimentan un incremento espectacular entre 2000 y 2003 . No son extraños los casos de ayuntamientos que multiplican por dos o por tres sus presupuestos en este periodo. Paradigmáticos resultan los municipios litorales y prelitorales del sur de la provincia de Alicante. San Fulgencio, por ejemplo, pasa de un presupuesto de 4,4 millones de euros en 2001 a casi 15 millones en 2003. Los ingresos aumentan considerablemente en aquellos epígrafes directamente relacionados con el proceso urbanizador: tasas sobre bienes inmuebles (impuestos directos) y sobre la construcción (impuestos indirectos). Estos últimos se incrementaron en un 700\% entre 1999 y 2000 (Ministerio de Hacienda y Administraciones Públicas, 2012). Paralelamente, y a un ritmo análogo al de los ingresos, aumentan todos los epígrafes englobados bajo el capítulo de gastos. Una atención especial merece el epígrafe «bienes y servicios» que engloba, a su vez, los subepígrafes «vivienda y urbanismo» $\mathrm{y}$ «medio ambiente», en donde se incluyen los gastos asociados al ajardinamiento de nuevas áreas así como el mantenimiento de las existentes. 
La fuerte dependencia del sector de la construcción se refleja en el notable incremento de las superficies entre 2000 y 2006, en el que ésta se multiplica por tres, y su posterior disminución a partir de 2007, cuando se ha reducido en una tercera parte (figura 8), coincidiendo con el estallido de la burbuja inmobiliaria. La superficie en 2010, último año con datos disponibles, no obstante, es superior a la de 1997, cuando se inicia la expansión urbanística. $\mathrm{Su}$ elevada rentabilidad frente a otros aprovechamientos explicaría su mantenimiento. Las causas de la significativa reducción de las superficies ocupadas por ornamentales en la provincia de Alicante son varias, a saber:

- Reducción de la demanda. Como ya se ha comentado en la introducción, el estallido de la burbuja inmobiliaria se ha traducido en una drástica reducción en la promoción de nuevos espacios urbanos y en el visado de nuevas viviendas. En esta misma línea, hemos de hacer mención a la notable disminución de ingresos de los ayuntamientos. De manera general, y si bien no son infrecuentes los dientes de sierra, los presupuestos de los ayuntamientos, con mayor o menor intensidad dependiendo de la mayor o menor afectación del boom de la construcción, de la pluralidad de sus actividades económicas y de su tamaño, se han reducido sensiblemente. En término medio, esta contracción puede cifrarse entre un 40 y un $70 \%$ del presupuesto medio de los años 2003-2005 para el caso de los ayuntamientos con mayor volumen presupuestario (Ministerio de Hacienda y Administraciones Públicas, 2012). La reducción en el apartado «impuestos indirectos» resulta muy ilustrativa ya que actualmente se sitúa, de manera general, en valores similares a los de finales de la década de los noventa, es decir, previos al boom inmobiliario. Continuando con el ejemplo anteriormente comentado, el ayuntamiento de San Fulgencio, ha pasado de unos ingresos en torno a 15 millones de euros en 2003 a unos 8,8 millones en 2012. La reducción en el epígrafe «impuestos indirectos», de 1,6 millones en 2005 a poco más de $370.000 €$ en 2012, resulta especialmente significativa. Esta disminución de ingresos y el mantenimiento de niveles de gastos elevados, se ha plasmado en el colapso de sus finanzas, en el incremento de su endeudamiento y en un proceso de reducción de gastos, que se ha acentuado en los últimos tres o cuatro ejercicios. Las cifras de los presupuestos municipales no reflejan la intensidad de este proceso. Ello es debido en gran medida a que está en parte matizado como consecuencia de la notable deuda contraída por parte de las administraciones con las empresas suministradoras. En ese proceso de aminoración de los gastos hay partidas más afectadas que otras. De estas últimas, la reducción de los servicios contratados con empresas de servicios de jardinería ha sido una de ellas, no tanto la que afecta al mantenimiento, como la de adecuación de nuevos espacios ajardinados. A esta disminución por parte de las administraciones públicas se une la notable reducción de la demanda de plantas ornamentales por parte de promotoras urbanas, que en muchas ocasiones han dejado numerosas promociones sin concluir coincidiendo con la crisis inmobiliaria. La no ornamentación de las urbanizaciones es uno de los ejemplos de promociones sin finalizar; si bien en muchos casos este procedimiento afecta a otras muchas fases de la adecuación urbanística e incluso, no son extraños la existencia de estructuras de casas abandonadas en medio de zonas de herbazal. Ambos factores se han traducido en una notable disminución 
en la adquisición de estos productos ornamentales. Ello es evidente, por un lado, en la contracción de superficies de cultivo, y, por otro, en el mantenimiento de éstas con las mínimas labores necesarias para de este modo, disminuir los costes asociados a su mantenimiento y evitar un abandono total a la espera de que remonte la demanda (figura 9). El carácter de plantas semi-silvestres de palmeras y olivos frente a otras plantas ornamentales permite esta práctica.

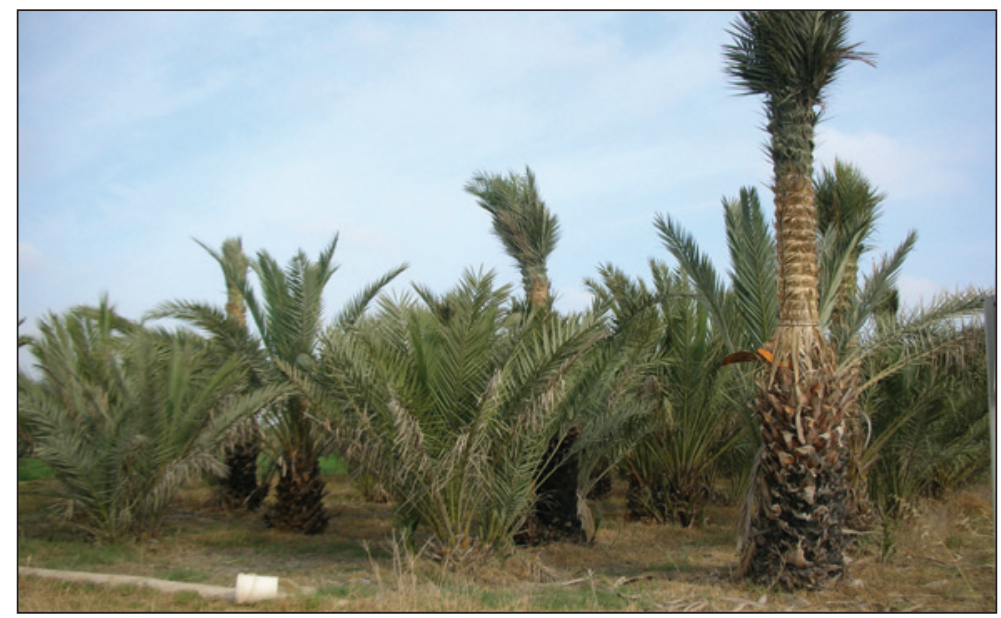

- Especialización en determinadas plantas ornamentales. Los productores de la provincia de Alicante han centralizado su producción en una gama de cultivos ornamentales reducida en la que predominan las especies arbóreas (palmeras y olivos) y, en menor medida, arbustos (entre las que destacan algunas variedades de nerium oleander, adelfas, muy utilizadas en la adecuación de carreteras y viales de acceso a áreas urbanizadas, y euonymus asociadas a setos de jardín) y flores (plantas aromáticas entre las que destacan el romero, rosmarinus oficinales, la lavándula o thymus, tomillo). Líneas de producción determinadas, en gran medida, por su intensa vinculación con la demanda de promotores y administraciones locales, pero, también, por los rasgos climáticos de estas tierras, que permiten maximizar los beneficios dada la cartera de plantas cultivadas.

- Disminución de la rentabilidad. El desplome de los precios de las palmáceas ha determinado bien su abandono, bien su reconversión hacia otras variedades de ornamentales o hacia las flores, en menor medida. Este descenso es resultado de la combinación de varias causas: la existencia de una oferta sobredimensionada a la demanda dada la notable reducción por parte de los consumidores habituales, el incremento de costes productivos asociados a la lucha contra el picudo rojo y la competencia ejercida por los productores italianos de diversas variedades de palmeras, especialmente las destinadas a ornamentación de interiores como la areca (Chrysalidocarpus 
Lutescens) y la kentía (Howea Forsteriana), que las comercializan a precios menores. Circunstancia que a su vez determina una menor capacidad de exportación hacia mercados tradicionales como Europa (en el caso de variedades de interior y exterior) e, incluso, Oriente Medio (variedades de exterior).

- Efectos asociados a la plaga del picudo rojo (Rhynchophorus ferrugineus). Este coleóptero de la familia curculionidae es una especie invasora procedente del sureste asiático que ha llegado a Alicante a través de palmeras infectadas procedentes de Egipto y, en menor medida, de otros países del norte de África. La plaga, que se detectó a finales de 2004 en la Comunidad Valenciana, afecta a las palmeras, sobre todo, a las variedades Phoenix Canariensis (palmera canaria) y a la Phoenix Dactylifera (palmera datilera), mayoritarias en el área de estudio. El ciclo biológico de este insecto, una vez la hembra adulta deposita entre 300 y 500 huevos de forma aislada en las hojas y eclosionan, se completa dentro del mismo hospedador. La larva se introduce en la palmera a través de heridas que ésta tenga, donde perfora galerías en el tronco que pueden alcanzar más de un metro de longitud. No es necesario cambiar de palmera hasta que ésta ha sido destruida en su totalidad, es decir, hasta que el animal se queda sin alimento suficiente para la cría de la siguiente generación o para el crecimiento del individuo. En el plazo de un año este escarabajo es capaz de completar hasta 3 ciclos biológicos. La legislación vigente en la Comunidad Valenciana la ha catalogado como «plaga de cuarentena» y, por tanto, su lucha y erradicación ha sido declarada de utilidad pública (Orden de la Conselleria de Agricultura, Pesca y Alimentación de 24 de Febrero de 2004, en base a la Ley 43/2002 de Sanidad Vegetal). En la actualidad, a pesar de los varios estudios llevados a cabo por diversas administraciones, no existe un método eficaz para combatirla. A falta de procedimiento seguro, además de aplicar tratamientos fitosanitarios, se procede a la eliminación de los pies afectados y de los que se sospecha pudieran estarlo, para evitar la propagación del insecto, lo que se ha traducido en arranques significativos de individuos adultos, aptos para su venta. Igualmente, se lleva a cabo un control exhaustivo del proceso de destrucción de los materiales de poda (generalmente por empresas especializadas) y de un tratamiento con insecticida de las hendiduras que origina la poda ya que son áreas muy sensibles a la deposición de huevos. La estricta legislación contra esta enfermedad, la aprobación de un protocolo de actuación tanto para empresas como para particulares (donde se señalan productos autorizados según uso y destino de la palmera, distribución temporal de los tratamientos y recomendaciones y tratamiento de los residuos de la poda) unido a los costes generados por la aplicación del protocolo han encarecido los costes de producción de este cultivo; reduciendo su rentabilidad y acentuando las pérdidas asociadas a la caída de demanda.

La reducción de las superficies ha sido resultado de la concatenación de varias de las causas arriba citadas; traduciéndose, en casos extremos, en el desmantelamiento de la totalidad de la explotación. Ilustrativo ha sido el arranque de toda la superficie ocupada por palmeras de una de las principales empresas comercializadoras españolas con sede en Sagunto (Valencia) a mediados de enero de 2013 (El País, 9-1-2013). La crisis del sector inmobiliario unido a la enfermedad que afecta a la palmera y la competencia ejercida por terceros países 
justifica la regresión de determinados cultivos de planta ornamental, sobre todo, las palmáceas y olivos, y su sustitución por otras ornamentales o por flores. Esos cambios se vinculan con otra característica de esta actividad económica como es su adaptación a las variaciones en la demanda y la marcada orientación al mercado. Ésta se ha traducido en la ampliación de las superficies destinadas al cultivo de plantas de interior y de temporada frente a las de árboles y arbustos. La menor duración del ciclo de cultivo y su coste de producción y su mayor demanda por parte de los particulares explica este incremento como resultado, en gran medida, de su mejor adaptación al cambio de ciclo inmobiliario (demanda básicamente privada frente a la de promotoras y administraciones públicas más centrada en grandes arbustos y árboles). En esta línea, se inserta, otras actuaciones como es la incorporación en los últimos años de la dimensión de la comercialización al detall por algunas explotaciones para incrementar su rentabilidad. Aumento que se relaciona con la demanda de plantas ornamentales por parte de un creciente número de propietarios de viviendas con jardín individual o urbanizaciones con áreas verdes comunes. También en esta línea, se enmarca la iniciativa adoptada por viveristas de Elche para crear una marca de calidad, para devolver la confianza al mercado sobre sus productos, pero también reducir los costes de su comercialización y la lucha contra el picudo rojo.

\section{III.2. Evolución de las superficies comercializadoras de planta ornamental}

El análisis de diversas fuentes estadísticas entre las que cabe citar las relativas a las superficies agrícolas publicadas por el gobierno regional y nacional y, sobre todo, las que tienen que ver con la comercialización de la planta ornamental (registro de actividades comercia$\operatorname{les}^{2} \mathrm{o}$ asociaciones que agrupan a productores, comercializadores y exportadores) reflejan notables dualidades territoriales desde el punto de vista de su localización como actividad productiva o comercial.

La característica principal derivada de la consulta de fuentes indirectas (estadísticas) y directas (entrevistas y trabajo de campo) es la nítida diferencia que se establece entre áreas productoras y espacios comercializadores. Las primeras se concentran básicamente en el sector sur de la provincia de Alicante, como se puso de manifiesto en el epígrafe anterior. Las segundas presentan una mayor variabilidad tanto en el tiempo como en el espacio. En este artículo, consideraremos como tales a los centros de jardinería, más conocidos por la denominación inglesa de «garden center», que corresponden a empresas especializadas en el diseño y mantenimiento de jardines, además de la venta y suministro de plantas y herramientas de jardinería. También, se incluyen las empresas de servicios que se dedican a diseñar y ejecutar obras de ajardinamiento y llevar a cabo el mantenimiento o conservación de zonas verdes. La incorporación de la venta directa por parte de algunas explotaciones determina que también éstas sean objeto de estudio en este apartado.

2 El registro de actividades comerciales ha sido suprimido por el artículo 3 del Decreto Ley 5/2012, de 6 de julio, del Consell, de medidas urgentes para el impulso de la actividad comercial y la eliminación de cargas administrativas (DOCV núm. 6814, de 9 de julio), por lo que ha desaparecido la obligación de inscripción de las actividades comerciales en el ámbito territorial de la Comunidad Valenciana. 
Tabla 2

VIVEROS Y ESTABLECIMIENTOS COMERCIALIZADORES (2011)

\begin{tabular}{|l|r|r|r|r|r|}
\hline & \multirow{2}{*}{$\mathrm{N}^{\mathrm{o}}$} & \multicolumn{4}{|c|}{$\mathrm{N}^{\mathrm{o}}$ Establecimientos comercializadores } \\
\cline { 3 - 6 } & viveros & Total & Garden center & Servicios & Producción y venta \\
\hline Bajo Vinalopó & 456 & 56 & 9 & 10 & 37 \\
Bajo Segura & 175 & 34 & 11 & 8 & 15 \\
Alacantí & 46 & 30 & 13 & 15 & 2 \\
Marina Alta y Baixa & 15 & 47 & 26 & 13 & 8 \\
Otras comarcas & 16 & 23 & 11 & 3 & 9 \\
\hline Total provincia Alicante & $\mathbf{7 5 0}$ & $\mathbf{1 9 0}$ & $\mathbf{7 0}$ & $\mathbf{4 9}$ & $\mathbf{7 1}$ \\
\hline
\end{tabular}

Fuente: Registro de productores de viveros y listado empresas comercializadoras. Elaboración propia.

Según el Registro de Productores de Viveros del Ministerio de Agricultura, Pesca y Alimentación a finales de 2005 había registrados 455 viveros autorizados en la Comunidad Valenciana. En 2011, esa cifra había ascendido a 1.168, de los que el 64\% se localizaban en la provincia de Alicante (MAGRAMA, 2012b). Productores que presentan una marcada concentración territorial, el $85 \%$ se localiza en los municipios de las comarcas meridionales y, más concretamente en uno de ellos, Elche, que aglutina al 57,3\% de todos los productores reconocidos como tales por el Ministerio de Agricultura. Los municipios más septentrionales (comarcas de la Marina Alta y Baixa), en cambio, tienen una presencia testimonial $(1,7 \%)$. Esta marcada concentración contrasta con los establecimientos que venden plantas ornamentales (tabla 2). Las diferencias se pueden resumir en un número de establecimientos significativamente inferior al reconocido como productores de viveros por el Ministerio de Agricultura, ya que forman parte de dos segmentos diferenciados (producción y comercialización) y, sobre todo, la no existencia de una nítida concentración en la localización de este tipo de establecimientos. El análisis de este epígrafe presenta ciertas dificultades inherentes, por un lado, al criterio al que se adscriben como empresas (garden, ajardinamiento interior, ajardinamiento exterior, diseño de jardines, etc.), que da lugar a la reiteración de empresas en diferentes epígrafes y, por otro, la prestación de más de un servicio comercial. Así, no es extraño que una empresa de servicios (asesoramiento de jardinería, diseño de jardines, etc.) disponga, en ocasiones, de sus propios viveros, que un garden center ofrezca servicios de asesoramiento o que una explotación comercialice directamente parte de su producción. Ello complica significativamente su análisis. Es posible, no obstante, deducir determinados rasgos (más cualitativos que cuantitativos) relacionados con la evolución de este tipo de establecimientos, localización o características más significativas .

Los establecimientos cuya actividad económica es estrictamente la comercialización tradicionalmente se han concentrado en las comarcas del norte de la provincia (Marina Alta y Baja). La expansión residencial desde finales de los noventa del siglo XX explica la difusión de este tipo de establecimientos por todo el sector litoral de la provincia y con una intensidad 
creciente en los sectores más meridionales. Ésta se vincula con las posibilidades de negocio al amparo de las actividades constructivas y la demanda de este tipo de productos asociados a la proliferación de tipologías donde el jardín es un elemento con presencia creciente, pero también la mayor disponibilidad de renta de la población. La crisis se ha plasmado en el cierre de algunos de estos establecimientos.

Este índice de concentración, si bien, se ha reducido en la última década al amparo del notable crecimiento urbanístico registrado en la década 1998-2008, evidencia la génesis y consolidación de dos modelos turístico-residenciales en la provincia de Alicante. El sector septentrional (Marina Alta y Baja), más antiguo, caracterizado, grosso modo, por el predominio de viviendas unifamiliares, en parcelas de dimensiones medias, donde la promoción particular ha sido intensa y muy elevada la presencia de jardines privados. El meridional (Bajo Segura), más reciente en el tiempo, definido por promociones de dimensiones medias con áreas comunes, donde las viviendas en altura y/o adosadas son mayoritarias. En esta última tipología, las áreas ajardinadas de las urbanizaciones son más reducidas. Es aquél, el que requirió desde principios de los años setenta plantas ornamentales para sus jardines. Ello explica la aparición de establecimientos especializados en la venta de plantas para estos habitantes, mayoritariamente procedentes del Centro y Norte de Europa, jubilados o prejubilados, que, en numerosas ocasiones, adquieren sus viviendas en los denominados municipios de segunda línea de costa ya que los sectores litorales estaban en gran medida ya ocupados con tipologías mas intensivas (bloques de apartamentos). La mayor tradición, desde el punto de vista turístico-residencial, se refleja en la importante presencia de garden center que responden a la tipología venta sensu stricto, que se completan con otras tipologías entre las que destaca comercialización más asesoramiento. Igualmente, se traduce en que sea en este ámbito territorial (norte de la provincia) donde se localicen los establecimientos más antiguos. La existencia de áreas productoras unido a la importancia que tiene la venta directa al público en general y minoristas (en torno a un $20 \%$ ), el carácter más tardío en la expansión residencial (desde finales de la década de 1990), pero a la vez la elevada intensidad del proceso de construcción de urbanizaciones en la última década se refleja en la importancia creciente que adquieren los establecimientos que combinan producción y venta en el sur de la provincia, el menor número de garden centers y su implantación más reciente.

Un análisis, aunque sucinto, de la información de este tipo de establecimientos obtenida de las diversas fuentes estadísticas consultadas, del trabajo de campo y de las entrevistas llevadas a cabo refleja una gran variedad interna, que dificulta la obtención de patrones dominantes nítidos. No obstante, es posible extraer las siguientes líneas de tendencia:

- tipología de la empresa. Si bien no aparece un patrón dominante, existen empresas dedicadas exclusivamente a la comercialización, pero también hay otras que compatibilizan venta y producción. Esta última opción se ha incrementado en la última década y, sobre todo, en el área meridional. Los productores contemplan la venta al detall como una actuación orientada a incrementar su margen de beneficios. Igualmente, son los productores de «plantas y pequeños arbustos» los que han adoptado en un mayor porcentaje esta doble opción. 


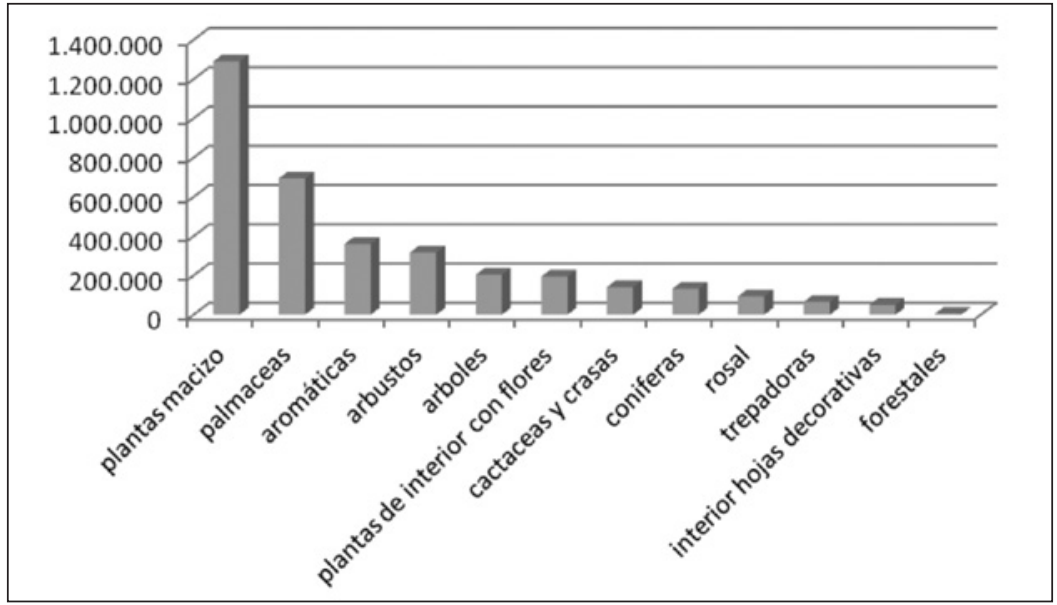

Fuente: Conselleria de Agricultura (Generalitat Valenciana). Elaboración propia.

- La cartera de productos suele ser amplia en cuanto a las variedades de plantas ofertadas (arbolado de porte medio-alto, arbustos y plantas pequeñas y palmeras y olivos) y a la diversidad de clientes hacia la que se dirige la oferta (público en general y minoristas, mayoritariamente, y, en menor medida, mayoristas e instituciones públicas). La distribución por grupos y géneros se vincula a la tipología de jardín dominante, en los que las condiciones climáticas (elevada radiación solar y pluviometría en torno a los $400 \mathrm{~mm} / \mathrm{año}$ ) y el precio del $\mathrm{m}^{3}$ de agua (importe creciente atendiendo a tramos de consumo, que penalizan consumos elevados y que se asciende a $1,57 € \mathrm{~m}^{3}$ para consumos domésticos entre 11 y $20 \mathrm{~m}^{3} / \mathrm{mes}$ y $1,96 €$ para los que superen los $20 \mathrm{~m}^{3} / \mathrm{mes}$, Boletín Oficial de la Provincia de Alicante, 2012) determinan la elección de plantas de bajos requerimientos hídricos. La tipología mayoritaria tanto en los jardines privados de chalets como en las áreas verdes comunes de las urbanizaciones de adosados es la constituida por la presencia de arbolado y arbustos que se complementan con flores y/o plantas aromáticas. Un sucinto análisis de los géneros dominantes (figura 10) en la comercialización de plantas ornamentales corrobora la tipología de jardín comentada. En el epígrafe «plantas de macizo», en realidad flores para exteriores, los géneros petunia, pelargonium (geranios) y viola (violetas) acumulan el 48,56\% del total de este apartado. Su reducido porte, que facilita su inserción en jardines de escasa superficie (mayoritarios en numerosas promociones en el sur de la provincia de Alicante), su precio asequible, la facilidad para su sustitución o el colorido que aportan sus flores explican su dominio en la comercialización de plantas ornamentales. En «palmáceas», el palmito (chamaerops humilis) y tres variedades de palmera (la Phoenix Canariensis, la Washingtoniana Robusta y Trachycarpus Fortunei) concentran el 77\% de las unidades vendidas en este epígrafe. En aromáticas, destacan el romero y la 
lavándula (48,35\%). En arbustos, nerium (adelfa) y euonymus acumulan el 60,73\% de este apartado. En arboles, mayoritaria es la utilización del olivo como planta decorativa $(44,53 \%)$.

Estos espacios ajardinados (de carácter privado), como nuevas naturalezas urbanas, reflejan las características climáticas de la zona y, en gran medida, evidencian diferencias notables con respecto a los jardines más tradicionales, de acceso público. El contraste más significativo es resultado en gran medida de la difusión de una tipología urbana extensiva que contrasta con la tipología urbana tradicional de carácter más concentrado. En esta última, la presencia de áreas verdes era lógicamente reducida y sus elementos ornamentales variaban según los gustos dominantes en la época en la que se diseñó el jardín. En la actualidad, el valor estético se ve condicionado a la elección de especies cuyos costes de mantenimiento, sobre todo, en áreas de gestión privada, no sea muy elevado y, por tanto, asumible por el propietario. La influencia de las condiciones climáticas explica, por ejemplo, que olivos y palmeras tengan una presencia notable como plantas ornamentales en los nuevos espacios verdes. Su carácter perennifolio y su adaptación a la aridez las convierten en plantas muy demandadas tanto por particulares como por la administración pública y promotoras urbanas para el nivel arbóreo de las áreas ajardinadas, dado su bajo consumo hídrico y su positiva valoración desde un punto de vista estético, ya que proporcionan un toque verde en áreas donde los tonos ocres resultan dominantes. El uso de palmeras como planta ornamental no es nuevo, ya que se remonta a finales del siglo XIX. Más novedosa resulta el empleo del olivo, cuyo uso se relaciona con su difusión como planta ornamental en áreas con condiciones climáticas no mediterráneas y su imitación en las mediterráneas, donde era un cultivo, pero nunca había formado parte de la ornamentación. El uso de flores de exterior y arbustos ha constituido desde siempre un ámbito de gran relevancia en la jardinería y conserva su trascendencia en los nuevos espacios verdes, ya que estéticamente aportan un gran colorido. Novedoso resulta la incorporación de algunas especies como pueden ser las plantas aromáticas, plantas adaptadas a la aridez, lo que facilita su cuidado y unos requerimientos hídricos bajos.

- Servicios ofertados. La cartera que ofrecen es amplia, ya que va desde la simple venta de plantas y productos de jardinería hasta el asesoramiento en la creación y mantenimiento de jardines tanto públicos como privados. Ésta se vincula, en gran medida, al tamaño de la empresa. Las primeras podrían equipararse a minoristas. Las que ofrecen servicios más allá de la venta (asesoramiento, venta e instalación, mantenimiento, etc.) se caracterizan por un número no muy amplio de empresas y presentan un marcado patrón de localización, que coincide con el área metropolitana de la ciudad de Alicante. Generalmente, corresponden a firmas de dimensiones medias que, en ocasiones, disponen también de viveros propios y, si bien, el asesoramiento a particulares se contempla como una línea de diversificación de la empresa, se vinculan mayoritariamente a iniciativas públicas (creación y mantenimiento de zonas verdes de ayuntamientos o diputaciones provinciales).

- Superficie. Los de mayor superficie se localizan en el sector meridional y en las proximidades de la capital provincial. Algunos de éstos se relacionan con explotaciones que han diversificado su actividad económica 


\section{CONCLUSIONES}

El análisis de la expansión de los usos turístico-residenciales se relaciona con la intensa actividad inmobiliaria que caracterizó a esta provincia, al igual que a gran parte del litoral mediterráneo español. El incremento de las superficies urbanizadas se ha asociado con el aumento de los espacios ajardinados como consecuencia de los procesos de adecuación urbana de estos nuevos espacios llevados a cabo por las administraciones públicas y promotoras, pero, también de particulares dada la importancia que han adquirido las tipologías de viviendas con jardín.

Las diferencias, desde el punto de vista de las dinámicas económicas y de evolución cronológica en la implantación de las actividades residenciales entre el sector norte y sur de la provincia, ponen de manifiesto realidades diversas atendiendo a criterios como la producción y comercialización de plantas ornamentales. El mantenimiento de un tejido agrícola en las comarcas meridionales con una clara orientación hacia el mercado explica la evolución hacia aprovechamientos de flores y planta ornamental directamente relacionada con la fuerte demanda de este tipo de aprovechamientos vinculados a la expansión residencial, que ha sido muy intensa en estas tierras desde finales de 1990. Esa interrelación se tradujo en una marcada expansión de las superficies ocupadas por planta ornamental y particularmente por olivos y palmeras. La crisis se ha dejando sentir en estas explotaciones, que han reducido la superficie cultivada o han sustituido algunas de las variedades productivas hacia la producción de flores y plantas de interior. Este proceso ha sido posible por la tradicional orientación al mercado de estas explotaciones y en aquellas en las que predominaban producción de ciclo productivo corto (flores y plantas de interior) y más compleja en las que dominaban los arboles. En este caso, junto al abandono y la sustitución de aprovechamientos, se ha observado la aminoración de las tareas realizadas en estas plantaciones para reducir costes. El carácter de plantas semi-silvestres de palmeras y olivos frente a otras plantas ornamentales permite esta práctica. Proceso que se refleja en la pérdida de peso relativo que la provincia de Alicante tiene en el contexto nacional de superficies ocupadas por flores y planta ornamental. La presencia de extranjeros que adquirieron a finales de los años sesenta parcelas en las que construyeron sus viviendas, generalmente unifamiliares, se plasmó en la aparición de establecimientos que ofertaban servicios y plantas para los espacios exteriores de las viviendas. La continuidad y acentuación de esta tipología urbana en el tiempo se ha plasmado en la existencia de los denominados garden center, que de manera excepcional se abastecen de sus propias explotaciones. La práctica más frecuente es adquirir los productos que ofertan a mayoristas o a productores (viveristas) de la propia provincia o de Valencia.

La cartera de productos ofertada por los productores como por las empresas comercializadores evidencia la especialización en una gama de plantas ornamentales (palmáceas, olivos, aromáticas y pequeños arbustos) que reflejan el carácter semiárido de este territorio. La elevada evapotranspiración de las plantas unido al precio del agua determinan unas tipologías de jardín dominantes, especialmente los privados (árboles, arbustos y plantas aromáticas) que requieren unos consumos de agua moderados. La presencia de jardines en los que el césped es predominante tiene una escasa presencia y, en muchos casos, se vincula a iniciativas públicas de adecuación de zonas ajardinadas. 


\section{BIBLIOGRAFÍA}

AGENCIA EUROPEA DE MEDIO AMBIENTE (EEA) (2003): Señales medioambientales 2002. Referencias para el milenio. Copenhague. Agencia Europea del Medio Ambiente. Disponible en: http://www.eea.europa.eu/www/es/publications/environmental_assessment_report_2002_9-sum

AGENCIA EUROPEA DE MEDIO AMBIENTE (EEA) (2006): Urban sprawl in Europe. The ignored challenge. Informe $n^{\circ}$ 10/2006. Copenhague. Agencia Europea del Medio Ambiente. Disponible en: www.eea.europa.eu/publications/eea_report.../eea_ report_10_2006.pdf

ALBARDIAZ SEGADOR, M.A. (1998): «El consumo de flores y plantas ornamentales en nuestro país», Estudios sobre consumo, n ${ }^{\circ} 44,98-104$.

ALBERT, A. y RULLÁN, O. (2007): «Nuevo modelo de producción residencial y territorio urbano disperso (Majorca 1998-2006)», en 9th International Geocriticism Symposium, Porto Alegre, 28 May-1 June. Disponible en: http://www.ub.edu/geocrit/9porto/artigues. htm

BOLETIN OFICIAL DE LA PROVINCIA DE ALICANTE (2012): Tarifas de abastecimiento domiciliario. Aguas de Alicante. BOP n ${ }^{\circ} 20$, de 30 de enero de 2012.

BURRIEL DE ORUETA, E. (2008): «La década prodigiosa del urbanismo español (19972006)», Scripta Nova, vol. XII, n 270 (64). Disponible en: http://www.ub.es/geocrit/sn/ sn-270/sn-270-64.htm

BURRIEL DE ORUETA, E. (2009a): «Los límites del planeamiento urbanístico municipal. El ejemplo valenciano», Documents d'Anàlisi Geogràfica, nº 54, 33-54.

BURRIEL DE ORUETA, E. (2009b): «La planificación territorial en la Comunidad Valenciana (1986-2009)», Scripta Nova. Revista electrónica de Geografía y Ciencias Sociales, vol. XIII, n 306,1 de diciembre de 2009. Disponible en: http://www.ub.edu/geocrit/sn/ sn-306.htm.

CONSELLERIA DE AGRICULTURA (2008): Plantas ornamentales comercializadas en la Comunidad Valenciana. Campaña 2007. Valencia. Generalitat Valenciana.

DOMENE, E.; SAURI, D. y PARÉS, M. (2005): «Urbanization and suistainable resource use: the case of garden watering in the metropolitan region of Barcelona», Urban Geography, $\mathrm{n}^{\circ} 26,520-535$.

DOMENE, E. y SAURÍ, D. (2007): «Urbanization and class-produced natures: vegetable gardens in the Barcelona Metropolitan region», Geoforum, $\mathrm{n}^{\circ}$ 38, 287-298.

GAJA, F. (2008): «El tsunami urbanizador de la costa mediterránea», Scripta Nova, vol. XII, $\mathrm{n}^{\mathrm{o}} 270$ (66), 1 de agosto de 2008.

GONZÁLEZ, J M. (2010): «The real estate and economic crisis: an opportunity for urban return and rehabilitation policies in Spain» Sustainability, $\mathrm{n}^{\circ} 2,1.571-1.601$.

HERNÁNDEZ HERNÁNDEZ, M. (2013): «Análisis de los procesos de transformación territorial en la provincia de Alicante (1985-2011) y su incidencia en el recurso hídrico a través del estudio bibliográfico», Documents d'Anàlisi Geogràfica, nº 59 (1), 105-136.

HERNÁNDEZ HERNÁNDEZ, M., MOLTÓ MANTERO, E.A. y RICO AMORÓS, A.M. (2008): «Las actividades turístico-residenciales en las montañas valencianas», Eria, ${ }^{\circ}$ 75, 77-97. 
HERNÁNDEZ HERNÁNDEZ, M. y MORALES GIL, A. (2009): «La hortofruticultura y las aguas del trasvase Tajo-Segura: repercusiones socioeconómicas», en: El trasvase Tajo-Segura: repercusiones económicas, sociales y ambientales en la cueca del Segura (Melgarejo Moreno, J., Dir.). Alicante. CAM Cultural, 413-464.

INDOVINA, F. (Coord.) (2007): La ciudad de baja densidad. Barcelona. Diputación de Barcelona.

INSTITUTO VALENCIANO DE EXPORTACIÓN (IVEX) (2012): Informe agroalimentario de la Comunidad Valenciana. Disponible en: http://www.ivex.es/estudios/informacion_sectorial_cv.html

KASANKO, M.; BARREDO, J.I.; LAVALLE, C., MCCORMICK, N.; DEMICHELI, L.; SAGRIS, V.; BREZGER, A. (2006): «Are European Cities Becoming Dispersed? A Comparative Analysis of Fifteen European Urban Areas», en Landscape and Urban Planning, $\mathrm{n}^{\circ} 77,111-130$.

MATA OLMO, R. (2007): Auge inmobiliario y evolución de los usos del suelo en España. Por una nueva cultura del territorio». Madrid. Universidad Autónoma de Madrid.

MELGAREJO MORENO, P., MATINEZ NICOLÁS, J.J. y MARTÍNEZ TOMÉ, J. (2004): «Productividad y rentabilidad de agua de riego en la provincia de Alicante». en Repercusiones socioeconómicas del Plan Hidrológico Nacional en la provincia de Alicante (Melgarejo Moreno, J, Ed.). Alicante. COEPA, 103-143.

MORALES GIL, A. (1997: Aspectos geográficos de la horticultura de ciclo manipulado en España. Alicante. Universidad de Alicante.

MUÑOZ, F. (2003): «Lock-living: urban sprawl in Mediterranean cities», Cities n 20 (6), 381-385.

NAREDO PÉREZ, J.M. (1996): «Metodología y resultados de la evaluación económica y ambiental de distintos sistemas de cultivo», en Cuadernos aragoneses de economía, $n^{o}$ 6(1), 41-76.

NAREDO PÉREZ, J.M. (1997): «La gestión del agua en España», Revista de Occidente, $n^{\circ}$ 194-195, 92-114.

NAREDO, J M. y MONTIEL, A. (2011): El modelo inmobiliario español y su culminación en el caso valenciano. Barcelona. Icaria.

RICO AMORÓS, A.M. (2002): «Insuficiencia de recursos hídricos y competencia de usos en la Comunidad Valenciana», Boletín de la Asociación de Geógrafos Españoles, $\mathrm{n}^{\circ} 33$, 23-35.

ROMERO, J., JIMÉNEZ, F. y VILLORIA, M. (2012): «(Un)sustainable territories: causes of the speculative bubble in Spain (1996-2010) and its territorial, environmental, and sociopolitical consequences», en Environment and Planning C: Government and Policy, $n^{\circ} 30(3), 467-486$.

TALTAVUlL DE LA PAZ, P. (2001): Economía de la Construcción. Madrid. Editorial Civitas.

VERA REBOLLO, J.F. y ESPEJO MARÍN, C. (2006). «El papel de los instrumentos de planificación en las dinámicas productivas y territoriales: Las Directrices y el Plan de Ordenación del Litoral de la Región de Murcia». En: Gobernanza territorial en España: Claroscuros de un proceso a partir del estudio de casos (Romero, J. y Farinós,. J., Eds.). Valencia. Publicacions de la Universitat de València, 61-79. 


\section{BASES DE DATOS}

ASOCIACIÓN PROFESIONAL DE FLORES, PLANTAS Y TECNOLOGÍA HORTÍCOLA DE LA COMUNIDAD VALENCIANA (ASFPLANT): http://www.asfplant.com/

CONSELLERIA DE VIVIENDA, GENERALITAT VALENCIANA (2012): Sistema de indicadores. 2. Disponible en: http://www.cma.gva.es/web/indice.aspx?nodo=61629\&idioma=C

DIRECTORIO DE PRODUCTOS Y SERVICIOS DE VIVEROS EN ALICANTE: http:// jardineria.vulka.es/alicante/viveros/

FEDERACIÓN ESPAÑOLA DE ASOCIACIONES DE PRODUCTORES EXPORTADORES DE FRUTAS, HORTALIZAS, FLORES Y PLANTAS VIVAS (FEPEX): http:// www.fepex.es/publico/portada/Portada.aspx

INSTITUTO ESPAÑOL DE COMERCIO EXTERIOR (ICEX): Estadísticas españolas de comercio exterior. Varios años. Disponible en: http://www.icex .es.

INSTITUTO NACIONAL DE ESTADÍSTICA (2012): Censos de población y viviendas, 2001 y 2011. Disponible en: http://www.ine.es/inebmenu/mnu_cifraspob.htm

INSTITUTO VALENCIANO DE ESTADÍSTICA (2012): www.ive.es

MINISTERIO DE AGRICULTURA, ALIMENTACIÓN Y MEDIO AMBIENTE (MAGRAMA) (2012a): Anuario de Estadística Agraria. Disponible en: http://www. magrama.gob.es/es/estadistica/temas/estad-publicaciones/anuario-de-estadistica/default. aspx\#para2

MINISTERIO DE AGRICULTURA, ALIMENTACIÓN Y MEDIO AMBIENTE (2012b): Registro Nacional de productores de semillas y plantas de vivero. Disponible en: http:// www.magrama.gob.es/es/agricultura/temas/medios-de-produccion/semillas-y-plantasde-vivero/registro-de-productores/

MINISTERIO DE FOMENTO (2012a): Estimación del parque de viviendas, 2001-2011. Disponible en: http://www.fomento.gob.es/BE2/?nivel=2\&orden=33000000

MINISTERIO DE FOMENTO (2012b): Viviendas principales y secundarias por comunidades autónomas y provincias. Disponible en: http://www.fomento.gob.es/ BE2/?nivel $=2 \&$ orden $=33000000$

MINISTERIO DE FOMENTO (2012c): Viviendas visadas. Disponible en: http://www. fomento.gob.es/BE/?nivel=2\&orden=09000000

MINISTERIO DE HACIENDA Y ADMINISTRACIONES PUBLICAS (2012): Datos presupuestarios de las entidades locales (2003-2012). Disponible en: http://serviciosweb. meh.es/apps/EntidadesLocales/ 
